
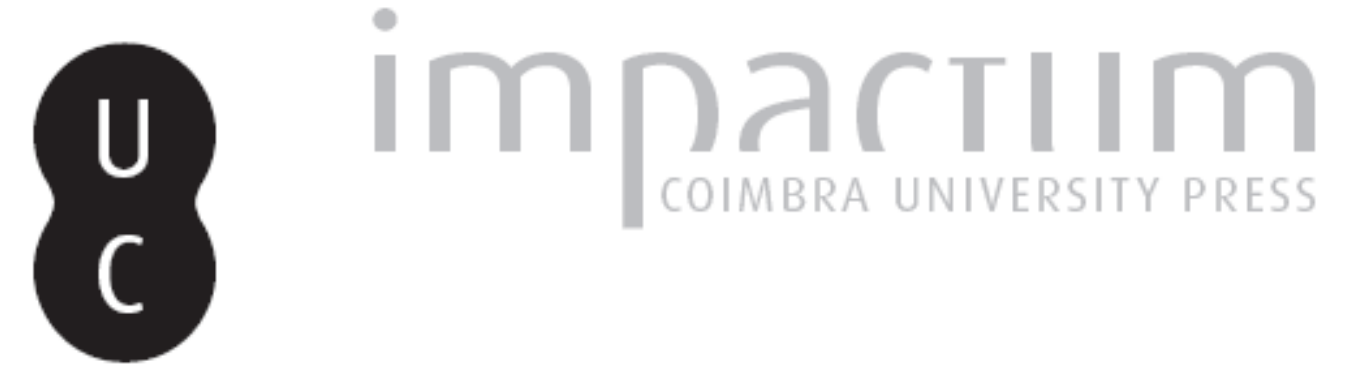

\title{
Duas inscrições inéditas encontradas em Serpins: (Lousã)
}

Autor(es): $\quad$ Monteiro, António João Nunes

Publicado por: Imprensa da Universidade de Coimbra

URL persistente:

URI:http://hdl.handle.net/10316.2/45726

DOI:

DOI:https://dx.doi.org/10.14195/1647-8657_19_6

Accessed : $\quad$ 26-Apr-2023 11:59:37

A navegação consulta e descarregamento dos títulos inseridos nas Bibliotecas Digitais UC Digitalis, UC Pombalina e UC Impactum, pressupõem a aceitação plena e sem reservas dos Termos e Condições de Uso destas Bibliotecas Digitais, disponíveis em https://digitalis.uc.pt/pt-pt/termos.

Conforme exposto nos referidos Termos e Condições de Uso, o descarregamento de títulos de acesso restrito requer uma licença válida de autorização devendo o utilizador aceder ao(s) documento(s) a partir de um endereço de IP da instituição detentora da supramencionada licença.

Ao utilizador é apenas permitido o descarregamento para uso pessoal, pelo que o emprego do(s) título(s) descarregado(s) para outro fim, designadamente comercial, carece de autorização do respetivo autor ou editor da obra.

Na medida em que todas as obras da UC Digitalis se encontram protegidas pelo Código do Direito de Autor e Direitos Conexos e demais legislação aplicável, toda a cópia, parcial ou total, deste documento, nos casos em que é legalmente admitida, deverá conter ou fazer-se acompanhar por este aviso.

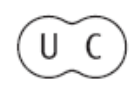


FACULDADE DE LETRAS

INSTITUTO DE ARQUEOLOGIA

CONIMBRIGA

VOLUME XIX

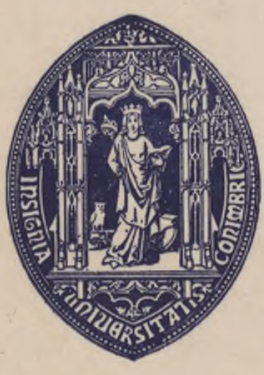

UNIVERSIDADE DE COIMBRA

1980 
António João Nunes Monteiro

Assistente da Faculdade de Letras de Coimbra

DUAS INSCRIÇÕES INÉDITAS ENCONTRADAS EM SERPINS

(LOUSÃ)

Conimbriga, xix, 1980, p. 163-172

ReSumo: Duas pequenas aras funerárias do século i d.C. encontradas em Serpins provêm de um local que pode ter sido castro romanizado. Nomina e cognomina merecem comentários do autor.

RÉSUMÉ: Deux inscriptions funéraires inédites du 1er siècle ap. J.C. ont été repérées par l'auteur dans l'église de Serpins, près de Lousâ. Un des cognomina, FLAWS, est l'objet d'une recherche approfondie. D'après la carte de répartition, il se trouve surtout dans le nord et l'ouest de la Péninsule Ibérique. 
(Página deixada propositadamente em branco) 


\section{DUAS INSCRIÇÕES INÉDITAS ENCONTRADAS EM SERPINS (LOUSÃ)}

A igreja matriz da freguesia de Serpins, concelho da Lousã, ergue-se no cimo de um morro - o Cabeço da Igreja — rodeado a Leste, Norte e Oeste pelo rio Ceira, local estrategicamente indicado para a implantação de um castrum. Este facto chamou-nos desde $\log$ a atenção, considerando que a existência do actual templo poderia muito provavelmente ser um indício da continuidade de povoamento ou, mais plausivelmente, o último estádio de uma sobreposição de cultos. Efectivamente, informar-nos-ia o P. António Maria Domingos, pároco de Serpins $\left({ }^{\mathrm{x}}\right)$, terem surgido as fundações de uma «capela», quando das obras de reconstrução da actual igreja. Embora não tenham sido anotadas quaisquer medidas ou esboçada planta desses vestígios, houve o cuidado de guardar os numerosos azulejos, que então surgiram.

Posteriormente - haverá uns quatro anos - foram construídos uns barracões, junto à igreja, no local conhecido por Cemitério Velho. Muitas pedras daí saíram e se perderam, sem terem sido devidamente observadas. Segundo nos disseram, os garotos distraíam-se a fazê-las rebolar pela íngreme encosta até ao rio. Houve, porém, algumas peças que foram poupadas e se encontram hoje guardadas na casa paroquial frente à igreja. Tivemos a ventura de aí descobrir, além de duas cabeceiras de ${ }^{(*)}$

(*) Agradecemos-lhe as valiosas informações que nos forneceu e a possibilidade de estudarmos o espólio arqueológico que salvaguardou. 
sepultura medievais, os fragmentos de duas pequenas aras funerárias romanas, de que damos notícia ${ }^{(2)}$.

1 - 1 - mais belo dos fragmentos (foto 1), cerca de metade do monumento, trabalhado num grés vermelho de grão fino, ostenta um capitel muito danificado e, no campo epigráfico, perfeitamente legíveis e bem conservadas, as duas primeiras linhas da inscrição. É ainda possível determinar o limite superior da terceira linha pelo vestígio, bem visível, da haste transversal da penúltima ou antepenúltima letra.

Dimensões (em centímetros): 24,5/21 X 24/17,5 X 13.

Sobre o que resta do campo epigráfico, com uma largura de $17,5 \mathrm{~cm}$ e uma altura máxima e mínima de $13 \mathrm{~cm} \mathrm{e} 8 \mathrm{~cm}$ respectivamente, está gravado o seguinte texto:

\section{L(ucii) GALLI(i) F/RONTO/[NIS ... E? vel F ?][...]}

De Lúcio Gálio Frontão...

Altura das letras: $1.1=3,6 ; 1.2=3,8 ; 1.3=0,7$ (o que resta). Espaços interlineares: $1=1,8 ; 2=1 ; 3=1,3$.

As capitais foram desenhadas com bastante esmero e perfeitamente alinhadas. $\mathrm{Na} 1.1, \quad \mathrm{o} A$ encontra-se picado, talvez por ocasião do desenterramento, mas tal facto não dificulta a leitura. $\mathrm{Na}$ 1.2, a primeira letra - um $R$ - deduz-se facilmente quer pela curvatura superior, que não foi abrangida pela fractura, quer pelo sentido; a terceira e quarta letras encontram-se em nexo (NT), certamente porque o ordinator pretendeu dar maior destaque ao cognomen e maior harmonia à disposição das letras. Este nexo forma um conjunto lelemente maior que as outras letras. Os 00 são de uma perfeição extraordinária. A1. 3, impossível de reconstituir na sua totalidade, deduz-se pelo vestígio da penúltima ou antepenúltima letra um $E$ ou um $F$.

$O$ facto da identificação deste personagem ser feita através dos tria nomina, omitindo a filiação, pode ser tomado como indica-

(2) Estamos em dívida para com o Dr. José d'Encarnação, nosso mestre e amigo, pela orientação neste estudo e estímulo para a sua publicação. 
tivo de se tratar de um liberto, nada desejoso de recordar a sua ascendência, ou de um peregrino.

0 nomen GALLIUS aparece-nos, na Península Ibérica, seguido por vezes de cognomen latino, como neste caso; contudo, julgamos dever salientar a significativa percentagem de inscrições em que tal não se verifica: efectivamente, em pouco mais de uma dezena de inscrições recolhidas por Hiibner( $\left.{ }^{3}\right)$, quatro delas apresentam este antropónimo seguido de cognomina não latinos, tratando-se, nalguns casos, de libertos. Este nomen é tipicamente latino, embora desconhecido nalgumas partes da Lusitânia ( $\left.{ }^{4}\right)$ : Untermann $\left(^{5}\right)$ notaria que o antropónimo GALLUS e os seus derivados — entre os quais se conta GALLIUS — só aparecem nas partes mais romanizadas da Península, ou seja, com maior incidência a sul, alguma dispersão ao longo da costa mediterrânica até Barcelona e na costa ocidental até ao rio Mondego.

O cognomen latino FRONTO é muito frequente na Península $\left(^{6}\right)$.

No respeitante à datação, julgamos pertencer este monumento ao séc. i d.C., atendendo ao perfeito tipo de letra e à omissão da fórmula D (iis) M [anibus) S(acrum).

2 - O segundo fragmento (foto 2) é também o que resta de outra pequena ara de proporções um pouco maiores que as do monumento atrás estudado. O material usado foi igualmente o grés vermelho de grão fino, certamente oriundo da mesma pedreira $\left({ }^{7}\right)$. A parte superior desta ara encontra-se muito dani-

(3) CIL II, p. 1063.

(4) R. Etienne e G. Fabre, Fouilles de Conimbriga, II, Paris, 1976, p. 73 .

(5) Untermann, Júrgen, Elementos de un Atlas Antroponimico de La Hispania Antigua, Madrid, 1965, mapa 41 (GALLUS), p. 111-112.

(6) Yer mapa de distribuição e m: Nelson Correia Borges, «Conimbriga», XY, 1976, p. 120.

$\left({ }^{7}\right)$ Acompanhou-nos nesta visita o nosso amigo António Duarte Sequeira, geólogo, a quem devemos a classificação dos materiais em que foram esculpidas estas aras, além de nos ter chamado a atenção para o facto das ombreiras da porta principal da igreja serem do mesmo tipo e características da rocha destes monumentos. Estas vieram de uma pedreira em Alveite Grande, Olho Marinho, no concelho de Vila Nova de Polares. 
ficada, sendo provável que apresentasse, inicialmente, duas pequenas volutas no capitel e, no topo, um fóculo, embora deste último não tenham subsistido quaisquer vestígios.

Dimensões: 28 X 29 X 17 .

O que nos resta do campo epigráfico resume-se a um tosco quadrado de lados acidentalmente arredondados, com uma altura de $22,5 \mathrm{~cm}$ e $29 \mathrm{~cm}$ de largura. Embora a superfície desta ara se encontre mais maltratada que a anterior, são perfeitamente legíveis as duas primeiras linhas, deduzindo-se uma terceira pá\}o vestígio superior de duas letras.

Leitura: FLAWS / LEPIDI F $\{$ Mus $)$ / ...[A?R?] ...

Flavo, filho de Lépido...

Altura das letras: 4,8. Espaços: $1=9 ; 2=2,5$.

Foi a harmonia a principal preocupação do ordinator. As letras, quer da 1.1 quer da 1.2 - e quase poderíamos dizer da 1. 3, observando atentamente os vestígios que dela restam - estão perfeitamente alinhadas e gravadas. Essa preocupação de harmonia é visível também na equidistância dos espaços interlineares bem posta em evidência na 1.2 onde o $D$ fica como que isolado, a uma aparente equidistância dos II que o ladeiam, formando a palavra LEPIDI um todo com o $F$ de filius, separado apenas por um bem distinto punctus distinguens.

$\mathrm{Na} 1.1$, o $A$ de FLAWS não apresenta a haste transversal, o que pode atestar a antiguidade deste monumento. Da 1. 3 nada mais nos resta que um pequeno vértice, $2 \mathrm{~cm}$ antes do vestígio da curvatura, provavelmente dum $R$. Inicialmente julgámos poder ler ANNORVM, ideia que afastámos por ser evidente a falta de espaço para tal número de letras; tratar-se-á da palavra MARITVS, não estando pois indicada a idade da personagem, como seria de esperar?

A personagem é identificada apenas pelo cognomen FLAWS, seguido da filiação, o que nos prova tratar-se de um indígena romanizado. Flavus pode ser de origem celta, se atendermos a que urna 
das suas variantes é FLAUS, considerado celta, que aparece em contextos indígenas $\left({ }^{8}\right)$. Aliás Kajanto $\left({ }^{9}\right)$ inclui Flavus entre os cognomes latinos, sublinhando porém a sua predominância na Península: 59 exemplos num total de 102 registados no conjunto do GIL. Em Conimbriga, uma importante inscrição $\left(10^{*}\right)$ menciona a oficina de um indígena Flavo, onde teria sido preparado o monumento. Em Thamusida, no Norte de África, menciona-se, num diploma militar, Flavus, soldado da Cohors II Hispana C. /?, natural da cidade autrígona de Virouesca, no norte da Península ( ${ }^{\mathrm{n}}$ ). A observação dos índices do CIL II (p. 1083) revela-nos como predominante a forma FLAVUS sobre todas as variantes numa proporção aproximada de 4 para 1 . Se atentarmos na distribuição do antropónimo Flaws e seus derivados, na Península Ibérica (mapa anexo p. 3A), julgamos poder salientar uma predominância a norte do Tejo e a NW da Península, não obstante os cinco exemplos de Tarragona. Não deixa de ser significativa a sua ausência, quase total, nas zonas mais fortemente romanizadas, como o caso da Bética, onde, como vimos, Gallus, se encontra largamente representado. Não nos parece, pois, forçada a hipótese de que os locais onde estes dois antropónimos se encontram referenciados com evidência, correspondam a pontos da Península onde se verificaria um maior contacto dos povos com um maior índice de romanização com outros de características celtas ainda bem acentuadas. Assim, sobressaem-nos, como principais focos de intercâmbio: Conimbriga (incluindo a Lousã, relativamente próxima), a zona de Mérida e Tarragona. Quanto à área da Lousã, julgamos assentar a sua importância na existência das minas de ouro, comprovadamente exploradas pelos romanos $\left({ }^{12}\right)$.

(8) Ver José d'ENCARNAÇão, Divindades Indígenas sob o Domínio Romano em Portugal Lisboa, 1975, p. 323.

(9) I. Kajanto, The Latin Cognomina, Helsínquia, 1965, p. 18, 37, 227.

(10) Fouilles..., II, n. ${ }^{\circ} 21$, p. 43-44. p. 206-208.

(u) José Maria Solana Sainz, Autrigonia Romana, Valladolid 1978,

(12) Gfr. Jorge Alarcão, Portugal Romano, Lisboa, 1973, p. 123. Como reforço da nossa hipótese, cfr. o que afirma José d'ENCARNAçÃo, a propósito da divindade ILURREDA (o.c., p. 200 a 203). 
Quanto ao cognomen que identifica o pai do falecido, LEPIDUS, embora tipicamente latino, não é muito frequente na Península Ibérica: Hübner (GIL II, p. 1085) apenas recolheu treze inscrições com este antropónimo ou seus derivados. A distribuição parece-nos dispersa por toda a Península, com insignificante representação no interior. No conjunto do mundo romano, Kajanto (13) recolheu pouco mais de uma centena de exemplos. Em Conimbriga, regista-se um oleiro com esse nome $\left({ }^{14}\right)$.

Atendendo ao tipo de letra, ao uso do nominativo e à omissão da fórmula $D$ (iis) $\mathrm{M}$ \{́anibus) $\mathrm{S}$ (acrum), atribuímos também este monumento ao séc. i da nossa era.

António J. Nunes Monteiro

(13) I. KAJANTO, O.C. p. 283.

(14) FOUILLES..., II, n. ${ }^{\circ} 185$, p. 128.

Conimbriga, 19 (1980), 163-172 


\section{LEGENDA DO MAPA}

Abreviaturas:

FG = Robert É TIENNE e Georges F A B RE, Epigraphie et sculpture (Fouilles de Conimbriga II) Paris 1976.

H = Aemilius Hü B Ne R, Corpus Inscriptionum Latinarum, II, Berlim 1869, Suplemento 1893.

ILER = José Vives, Inscripciones Latinas de la España Romana, Barcelona, I, 1971, II 1972.

RIT = Géza ALFÕLDY, Die Rõmischen Inschriften von Tarraco, Berlim 1975.

1 - SERPINS (Lousa) (inédito)

2 - CONIMBRIGA: H 372, ILER 4925, FC n. ${ }^{\circ}$ 50; H 366, ILER 4861, $F C$ n. ${ }^{\circ} 39 ; F C$ n. ${ }^{\circ}$

3 - GOLLIPO (Batalha): H 355, ILER 4019

4 -BE JA: ILER 3627 (*)

5 -BENGANTEL (Vila Viçosa): H 5211, ILER 4154

6 -MÉRIDA: $H$ 5226, ILER5647a

7 - CÁCERES: $H$ 750, ILER 4090

8 -VALÊNCIA DE ALCANTARA: ILER 5970

I -IDANHA: ILER973

10 -IDANHA: ILER4854

11 CÓRIA: $H$ 787, ILER 4370; $H 778$

12 -TALAVERA DE LA REINA: $H$ 908,

4274

13 -BEJAR (Salamanca): H 882, ILE4076

14 -SEGÓVIA: H 2729, ILER5277

15 - HINOJOSA DE DUERO: ILER3236

16 - FRESNADILLO (Zamora): ILER2344

17 - MORAL: H2625

18-MORAL: H 2620, ILER6580

19 - VILLALCAMPO (Zamora): ILER 6723

20 -BRAGANÇA: $H$ 2502, ILER 4429

21 — LAGOMAR (Donai — Bragança): H 6293, ILER 2298

22 - SACOIAS (Baçal — Bragança): H 5620, ILER 2641

23 -CHAVES: H 2486, ILER 5033

24 - S. MARTINHO DE VÁRZEA DO DOURO (Marco de Canaveses): H 2376, ILER $136{ }^{\left({ }^{2}\right)}$

25 - SANTA COMBA (Paredes): ILER 5083b

26 - CALDAS DE VIZELA (Guimarães): H 2405, ILER 658; H 5557

27 —SERZEDELO (Guimarães): H 5562, ILER 787

(*) — Na opinião de J. d'Encarnação, esta inscrição não é de Beja, mas sim da província de Cáceres; incluímo-la, pois, com muitas reservas.

(2) No ILER é erradamente indicada como sendo de Coimbra. 
28 - S. MIGUEL-O-ANJO (V. N. Famalicão): 5561, 770

29 -BANDE: ILER63

30 - SANTA EUFEMIA DE AMBIA (Orense):

5977

31 - ORENSE: $H$ 2526, ILER 647

32 - SAYAR (Pontevedra): ILER985

33 -PONTE DO NAVIA (Galiza): 16340

34 -POSTIGO Y MIÑA: $H$ 5644,

35 - VILLALIS (Léon): $H 2553=2556$, os mesmos indivíduos)

36 -LEÓN: H 2669, ILER4692; H 5688

37 -LEÓN: ILER4498

38 - PUEBLA DE LILLO (León): $H$ 5675,

39 - ABLANEDA (Astúrias): H ILER 5632

40 - CORÃO (Astúrias): H 2712, ILER 5436

41 -LLÉNIN (Astúrias): H 5753, ILE5847

42 -SEGISAMA: H 5812, ILER2825

43 CORUNHA DEL CONDE (Burgos): H 2774,

44 -LARA DE LOS INFANTES (Burgos): $H 2864$, ILER 2353; H 5800

45 -LARA DE LOS INFANTES: $H 2852$,

46 -SAN ESTEBAN(SORIA): H2814, 192

141

$25=27(2$ exemplos com

3500

17

5320; H 2868,

6372

47 -TRICIO: $H 2889$

48 -MIRANDA: H 2924, ILER959

49 -SARAZO (Alava): ILER6773

50 - SALVATIERRA (Alava): $H$ 2943,

2576

51-ANGOSTINA (Alava): ILER6780

52 - -MARAÑON (Navarra): ILER 4746

53 - ARELLANO (Navarra): ILER 5752

54 - ESLAVA (Navarra): ILER 57

${ }_{55}$-SANTACARA (Navarra): $H 2964$,

56 - BUJARRABAL (Siguenza): $H 2847$

57 -BARCELONA: ILER5231; H 4523, ILER 5555

58 -TARRAGONA: $H$ 4332, ILER6438, 368

59 _ TARRAGONA: $H 4168=3587, \quad 5619=5643, \quad 199 ;$ ILER 395, RIT43; RIT210; H4192, ILER 1323, 330

60 -TORTOSA (Região): H4022, 14563

61 - JÁTIVA: H 3626, ILER5409

62 -GUADIX: H 3395, ILER 5517

Não assinaladas por dificuldade de localização rigorosa:

A LUSITÂNIA (Região de Cáceres?): $H$ 950,

O SAN FRUTOS (Léon?): $H$ 5673, 2303

A SANTA MARIA DE CONDADO (Galiza):

6005

O FUENTES, mus. S. Vicente: 


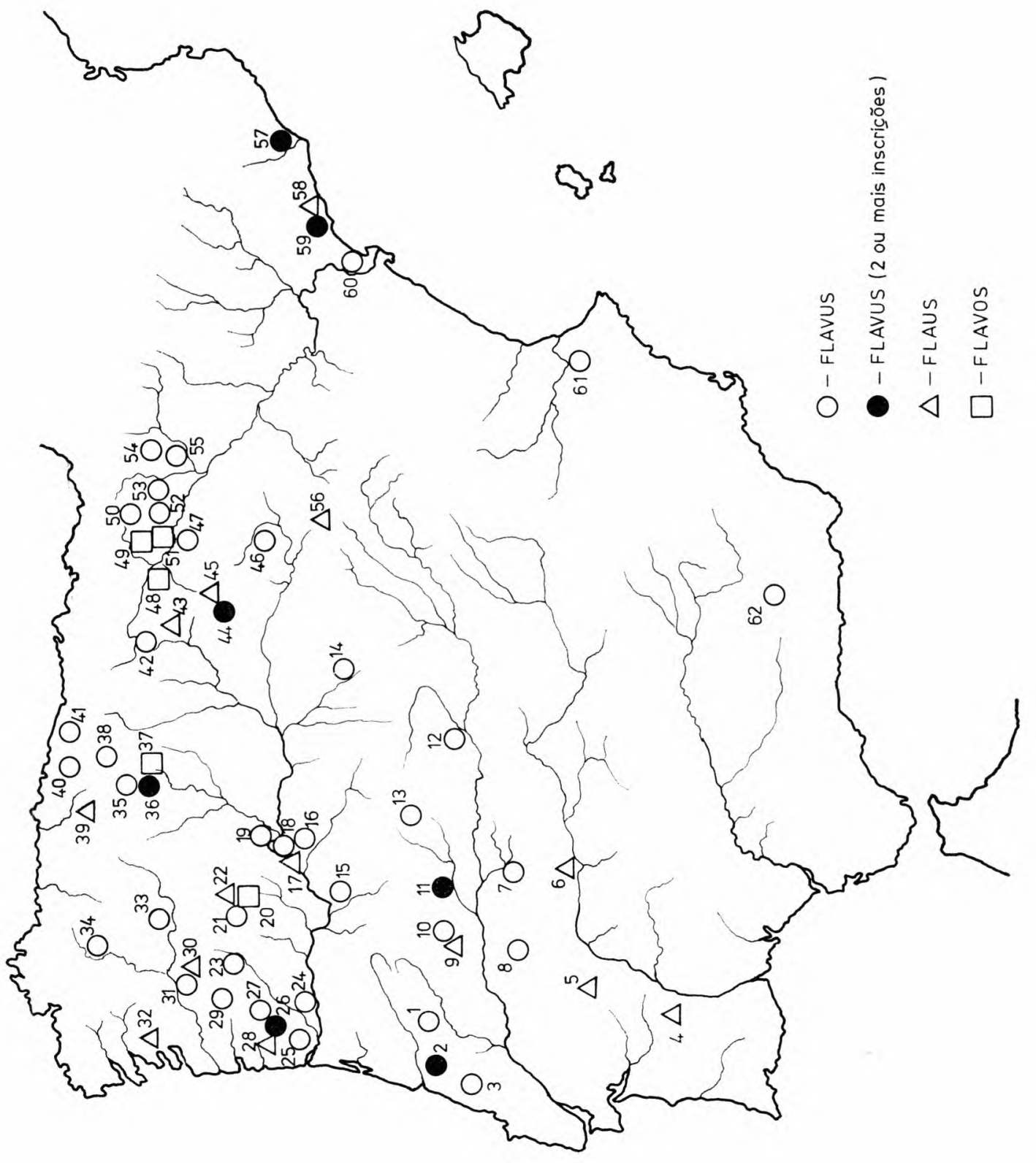


(Página deixada propositadamente em branco) 

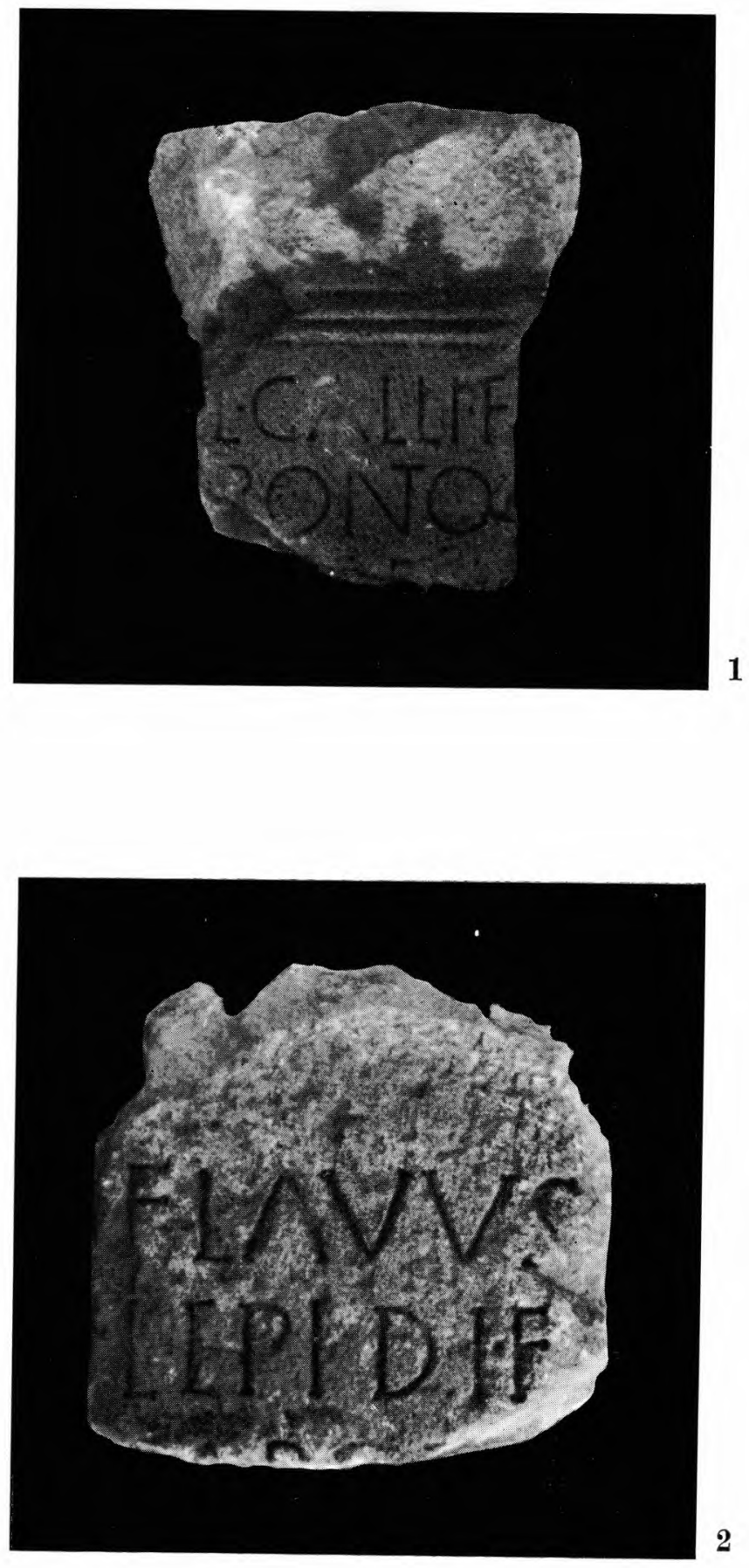